\title{
Совершенствование
}

\section{нормативно-правовой базы в области метрологической экспертизы}

\author{
Рассказывает руководитель отдела обеспечения единства \\ измерений ФГУП «МНИИРИП» Владимир Васильевич Быканов
}

\begin{abstract}
Всемирный день метрологии отмечается 20 мая. Эта дата напоминает нам, что вся деятельность человека тесно связана с измерением физических величин, необходимых в качестве исходной информации для управления процессами, проектирования, принятия решений. Без точных измерений невозможно представить создание инновационных продуктов в области техники и технологий.

О нормативно-правовой базе в области метрологической экспертизы (МЭ), трудностях на пути реализации метрологических интересов, определяющей роли метрологии в обеспечении качества на всех этапах жизненного цикла электронной компонентной базы рассказал руководитель отдела обеспечения единства измерений ФГУП "МНИИРИП", к. т.н., с. н.с. Владимир Васильевич Быканов.
\end{abstract}

В большую метрологию Владимир Васильевич пришел в 1981 году, после окончания военно-космической академии им. А.Ф. Можайского он начал работать в 32-м ГНМЦ Минобороны России, занимался перспективным направлением - метрологическим обеспечением сложных измерительных систем. Вместе с коллегами участвовал в создании примерно 50 эталонов. Принимал участие в сопровождении разработки квантово-оптических систем (КОС), которые измеряют расстояние до космических аппаратов, летающих на высокоэллиптической орбите. Сейчас он руководит отделом обеспечения единства измерений во ФГУП «МНИИРИП».

Владимир Васильевич, расскажите, пожалуйста, какие функции выполняет в МнИИРИП ваше подразделение?

ФГуп «МНИИРИП» по заказу Департамента радиоэлектронной промышленности Минпромторга России занимается исследованиями, осуществляет научно-методическую координацию работ по созданию и проведению испытаний ЭКБ. На предприятии функционирует собственный испытательный центр, который, по моему мнению, в образцовом состоянии. У нас проводится аттестация испытательного оборудования, поверка приборов. Мы используем уникальное измерительное и аналитическое оборудование, которое в России представлено в двух-трех экземплярах

Отдел обеспечения единства измерений занимается вопросами метрологического сопровождения разработки, испытаний, производства ЭКБ Во-первых, проводится метрологическая экспертиза технической или конструкторской документации; во-вторых, - метрологическая экспертиза реальных объектов: проверка продукции, измерительных приборов и других материальных объектов на соответствие требованиям нормативных документов.

Перед нашим отделом поставлены следующие ключевые задачи. Первая - в МниИриП более 40 комплектов испытательного оборудования, причем есть абсолютно оригинальное оборудование. Мы должны периодически проводить его аттестацию. Вторая задача - поверка всех приборов нашего испытательного центра. Третья - экспертиза конструкторской, технологической документации на всех этапах ОКР по разработке ЭКБ 
и РЭА, которые сопровождают МНИИРИП по заказу Минпромторга РФ.

Как вы оцениваете ситуацию с метрологической экспертизой в радиоэлектронной отрасли в целом?

Так как ФГУП «МнИИРИП» выполняет исследования, осуществляет научно-методическую координацию работ по созданию и проведению испытаний ЭКБ, необходимо было проанализировать ситуацию с метрологическим обеспечением в радиоэлектронной отрасли. Такой анализ был выполнен в 2017 году. Опрос специалистов 156 организаций позволил нам собрать важные сведения, касающиеся МЭ разрабатываемых образцов ЭКБ и РЭА. В результате выяснилось, что только девять организаций проводят ее без серьезных нарушений. Стоит напомнить, что Федеральный закон № 102-Ф3 "Об обеспечении единства измерений" вступил в силу в 2008 году, в статье четко прописано, что обязательной МЭ должна подвергаться проектная, конструкторская, технологическая документация разрабатываемых изделий, находящихся в сфере государственного регулирования. К сожалению, пока данному вопросу уделяется недостаточно внимания.

Что же мешает улучшить ситуацию с реализацией метрологических интересов?

В ст. 14 Ф3-102 определено понятие «Обязательная метрологическая экспертиза". Данный документ является законодательным. Другие акты в сфере МЭ носят нормативный характер. У нас есть два: ГОСТ РВ 8.573-2000 - «Метрологическая экспертиза технической документации образцов вооружения и военной техники", а также РМГ 63-2003 ГСИ - рекомендации по межгосударственной стандартизации, описывающие обеспечение эффективности измерений при управлении технологическими процессами. Подчеркну, что и в документе РМГ 63-2003, и в ГОСТ РВ 8.573-2000 нет указаний на то, что экспертиза является обязательной. Конечно, издано постановление Правительства РФ № 780 "Об особенностях обеспечения единства измерений при осуществлении деятельности в области обороны и безопасности РФ». Однако перечисленных документов на сегодняшний день недостаточно, чтобы навести порядок в части проведения качественной Мэ. Поэтому коммерческие организации выполняют ее силами своих метрологов. Иногда формально, иногда нет, но в основном для проформы. Приведу пример: в 2018 году в 10 из 12 проведенных
ФГУП «МНИИРИП» метрологических экспертиз технической документации разрабатываемых ЭкБ и РЭА были выявлены нарушения.

В настоящее время только Минобороны России исполняет требования Ф3-102 в полном объеме. Ситуацию изменил подписанный Сергеем Шойгу приказ «Об установлении Порядка проведения обязательной метрологической экспертизы военной техники и ее технической документации". Была выстроена вертикаль взаимодействия Главного научного метрологического центра (ГНМЦ) с военными институтами по всем видам войск в вопросах проведения обязательной МЭ.

Какие меры принимаются для решения этих проблем и какие вопросы нормативного обеспечения стоят перед метрологами радиоэлектронной отрасли?

Эффективным инструментом исполнения закона Ф3-102 в радиоэлектронной отрасли станет «Руководство о порядке проведения обязательной метрологической экспертизы технической документации на изделия радиоэлектронной аппаратуры и электронной компонентной базы», разработанное в 2018 году ФГУП «МНИИРИП» по поручению Минпромторга РФ. Данный документ, согласованный с ведущими предприятиями, военными экспертами, находится на рассмотрении руководителей Минпромторга России. Если документ утвердят, он станет руководством для предприятий радиоэлектронной промышленности к выполнению требований Ф3-102 в отношении обязательной Мэ.

\section{Перед нашим отделом поставлены следуюшие ключевые задачи. Первая - периодическая аттестация испытательного оборудования, находящегося во ФГУП "МНИИРИП". Вторая - поверка всех приборов нашего испытательного центра. Третья - экспертиза конструкторской, технологической документащии на всех эmanax OKP nо разработке}

Еще одна проблема нормативного обеспечения отраслевой МЭ - в дополнение к Федеральному закону № 102-Ф3 «Об обеспечении единства 
измерений" необходим актуальный единый документ с описанием требований к аттестации методик измерений. Есть приказ Минпромторга РФ от 15 декабря 2015 года № 4091 «Об утверждении Порядка аттестации референтных методик (методов) измерений". Однако, существуют стандарты, выпущенные около 30 лет назад. Например, гОСт 20271.1-91 предусматривает более 30 методов измерений электрических параметров изделий СВч. Вместе с тем СВч-техника с учетом внедрения новых технологий развивается очень динамично. У приборов новые характеристики, а ГОСТ создан более 25 лет назад. В нем не прописана обязательная аттестация методик косвенных измерений, поэтому предприятия отказываются ее проводить. Но необходимость аттестации методик не нами придумана, а, напомню, указана в вышеназванном приказе № $4091 \mathrm{Mин-}^{-}$ промторга РФ. На том и стоим. Ведь если неверно выбран параметр, неправильно проведены из-

\section{С точки зрения решения} задач развития контрольноизмерительной аппаратуры и средств ее метрологического обеспечения целесообразно создание 35 современных эталонов, автоматизированных комплексов, формирование единого центра испытаний новейших элементов

РЭА и ЭКБ и единого перечня ЭКБ для приборостроительных организаций

мерения - на выходе получается некондиционная компонентная база. Такие изделия ЭКБ, например, нельзя использовать в высокоточной аппаратуре. Необходимо понимать, если в геометрических размерах допущены ошибки даже на несколько миллиметров, то впоследствии погрешность увеличивается в разы. В результате сантиметры превращаются в метры, погрешности в углах - в километры и т.д.

Однако зачастую руководители предприятий понимают метрологическое обеспечение как работу по проведению поверки или калибровки имеющегося парка средств измерения, аттестации испытательного оборудования. Тогда как необходимо заниматься именно вопросом метрологического обеспечения с привлечением новых средств измерения, разработкой новых методов, испытаний, исследований. К сожалению, пока это не делается. На встречах с главными метрологами предприятий они признают тот факт, что в отрасли недостаточное внимание уделяется этому важному аспекту. Мы проводили в МнИирИП семинар по данной тематике, приглашали на него метрологов. Руководители предприятий отвечали: "Нет денег, чтобы оплатить участие специалистов".

В марте этого года специалисты ФГУП «МНИИРИП» проверяли состояние метрологического обеспечения одного головного предприятия радиоэлектронной отрасли. Среди наших замечаний есть довольно существенные: стандарт «Метрологическое обеспечение предприятия" не гармонизирован с нормативными документами, не соответствует деятельности этой организации в области метрологии, последний раз документ корректировался в 2001 году. Метрологическая экспертиза, мягко говоря, тоже проводится с нарушениями.

Вы затронули такой актуальный вопрос, как обеспечение метрологов современными, модернизированными средствами измерения. Теоретики и практики сходятся во мнении, что тяжелые реформы 90-х годов фактически разрушили научную, технологическую и материальную базу приборостроительной отрасли. На ваш взгляд, какая ситуация сейчас сложилась в этой сфере?

Весь спектр измерительных задач геометрических параметров я разделил бы на четыре группы.

Первая группа - общие измерительные задачи, характерные как для ЭКБ, так и для множества других объектов: измерение массы, геометрических размеров, электрических, радиотехнических величин ит. п. Разработаны отечественные средства метрологического обеспечения, поэтому состояние дел в этой сфере вполне благополучное.

Вторая группа - специальные измерительные задачи, характерные для современной электрои радиотехники, информационных технологий: генерирование сигналов большой амплитуды, измерение параметров цифровых микросхем и модулей, глубокого вакуума, характеристик спецстойкости, информационной безопасности и т. п.

Третья группа - комплексные измерительные задачи: измерение уровня индустриальных помех, 
параметров переходных процессов, динамических характеристик ЭКБ, антенные измерения и т. п.

Наиболее проблемными являются специальные и комплексные измерительные задачи, рациональный путь решения которых - создание автоматизированных измерительных систем на базе современных средств измерения и размещение их на базе специализированных предприятий, например, во ФГУП «МНИИРИП».

Четвертая группа - измерения в СВЧ-диапазоне. В этой сфере сложная ситуация со средствами измерений. Например, для диапазонов около 100 ГГц у нас пока не разработаны эталоны. Если говорить о частотах в диапазоне от 18 до 118 ГГц, то доля импортных классических измерительных средств достигает 75\%.

С точки зрения решения задач развития контрольно-измерительной аппаратуры и средств ее метрологического обеспечения целесообразно создание 35 современных эталонов, автоматизированных комплексов, систем и средств измерений параметров перспективной РЭА и ЭКБ, формирование при Минпромторге России единого центра испытаний новейших элементов РЭА и ЭКБ, формирование единого перечня ЭКБ для приборостроительных организаций.

Владимир Васильевич, а у экспертного сообщества есть собственное видение решения задачи развития и совершенствования метрологического оборудования?

Для решения этой актуальной задачи необходимо серьезное финансирование. Мы сотрудничаем с Российской академией наук по СвЧ-тематике. Для проведения исследований и продвижения новых направлений нужна отечественная аппаратура. Согласно требованиям Ф3-102 все средства измерения, применяемые в сфере государственного регулирования обеспечения единства измерений, должны быть утвержденного типа, работоспособны, поверены, снабжены действующими свидетельствами о поверке. Тогда как импортные средства измерения неутвержденного типа мы можем только откалибровать: оценить метрологические характеристики в заданном диапазоне. Однако калибровка в сфере государственного регулирования запрещена. Соответственно импортные средства измерений с необходимыми высокими метрологическими характеристиками, закупаемые радиоэлектронной отраслью, хотя и калибруются, но запрещены к применению при испытаниях и производстве ЭКБ. Получается заколдованный круг. Отечественные средства измерения с соответствующими метрологическими характеристиками не разрабатываются из-за отсутствия ЭКБ с требуемыми параметрами, а закупаемые импортные приборы неутвержденного типа применять нельзя.

\section{В приборостроительной отрасли необходимо создать совет главных конструкторов. Совет сможкет проводить единую техническую политику, сообща анализировать воплощаемую вертикаль: от эталонов до рабочих средств измерений}

Поэтому требуется разработать собственную вертикаль: от эталона - средства измерения, которое отличается наивысшей точностью воспроизведения единицы физической величины, - до рабочего средства, используемого разработчиками нашей аппаратуры. Сложный капиталоемкий вопрос требует времени. Над решением этой задачи трудятся Росстандарт, ВНИИФТРИ, другие метрологические институты, есть успехи, но и сложностей достаточно.

Что, по вашему мнению, можно сделать в организационном плане для развития и совершенствования метрологической экспертизы?

В приборостроительной отрасли необходимо создать совет главных конструкторов. Эту инициативу профессиональное сообщество активно обсуждает на конференциях и форумах. Почему? Совет сможет проводить единую техническую политику, сообща анализировать воплощаемую вертикаль: от эталонов до рабочих средств измерения. Ведь прежде чем принять научно-техническое решение, необходимо удостовериться, что оно верное и послужит гарантией прорыва по наиболее важным и актуальным направлениям в приборостроении.

Пока же над решением главных на сегодняшний день вопросов мы трудимся разобщенно: институты в системе Росстандарта - в собственном ведомстве, приборостроительные организации - у себя на местах, а мы во МнИИРИП - на своем предприятии. Объединив усилия, мы смогли бы быстрее создать единый перечень электронной компонентной базы для приборостроительной отрасли: аналого-цифровые преобразователи, 
цифро-аналоговые преобразователи, интегральные микросхемы, сверхбольшие интегральные микросхемы и т.д. Это целесообразно сделать для развития приборостроительной отрасли.

Опираясь на ваш профессиональный опыт, расскажите, как выбрать организацию для проведения обязательной метрологической экспертизы и работает ли принцип конкуренции при выборе такой организации?

Во-первых, государство приняло Федеральный закон "Об аккредитации организаций в области обеспечения единства измерений". Для его исполнения создано федеральное агентство «Росаккредитация", которое проводит экспертизу, анализ, оценивает компетентность специалистов предприятий в области проведения обязательной МЭ. Результатом такого аудита является выдача аттестата аккредитации, на основании которого можно осуществлять работы по обязательной МЭ. В частности, ФГУП «МНИИРИП» проводит МЭ проектной, конструкторской, технологической и другой технической документации для ЭКБ И РЭА.

Во-вторых, необходимо обратить внимание на такой пункт, как область аккредитации, которая также прописывается в документе. Аттестат аккредитации по проведению МЭ позволяет нам четко исполнять ст. 14 Федерального закона «Об обязательной метрологической экспертизе».

\section{Роль и значение метрологического обеспечения радиоэлектронной отрасли будут возрастать}

Надо отметить, что работающий в условиях рынка принцип конкуренции актуален и при выборе предприятия для проведения МЭ. Однако в радиоэлектронной отрасли в вопросах метрологического обеспечения предприятий должна быть собственная эталонная организация. Такой подход позволил бы создать единый центр, который как верховный судья решал бы спорные вопросы.

Например, прибор МКМ-т представляет собой масс-спектрометрический комплекс, основная функция которого - контроль состава влаги в подкорпусном пространстве микросхем и полупроводниковых приборов. В России таких установок не более девяти, однако каждая выдает свои показатели измерений. Нужно навести порядоксоздать единый эталонный центр, куда в случае возникновения спорных вопросов можно было бы привозить радиоэлектронные изделия для испытаний по тем или иным параметрам. Таким эталонным центром мог бы стать наш испытательный центр.

Как решается кадровый вопрос? Существует ли проблема нехватки молодых специалистовметрологов в МнИИРИП? Удается ли научному институту привлекать на работу молодых и талантливых выпускников?

Могу без преувеличения сказать, что у специалистов испытательного центра МНИИРИП высокая квалификация и многолетний опыт работы. Важное преимущество - наличие современного оборудования, средств измерения, гарантирующих точность результатов испытаний. Поэтому я считаю наш испытательный центр эталонным. Очень надеюсь, что он получит этот статус официально. Наряду с этим у нас имеется серьезный научный потенциал в области метрологии. С нами сотрудничает уважаемый Виктор Николаевич Храменков, заслуженный метролог Российской Федерации. Ряд высококвалифицированных специалистов знают, как качественно и без ошибок проводить экспертизы.

Постепенно решается и проблема привлечения молодых, талантливых выпускников вузов к работе в нашем институте. Я два с половиной года читаю курс по метрологии в Мгту им. Н. Э. Баумана. Естественно, приглядываюсь к студентам, рассказываю о наших идеях. Три молодых специалиста уже работают в нашей организации. Все очень способные, перспективные, с красными дипломами. Надеюсь, во МнИИРИП они получат необходимые навыки и станут настоящими метрологами.

В заключение хочу отметить, что для решения задачи метрологического обеспечения промышленности в ближайшие десять лет у нас есть и резервы, и потенциал. Сегодня нужно объединить усилия для преодоления стоящих перед отраслью проблем.

Еще раз хочу подчеркнуть, что роль и значение метрологического обеспечения радиоэлектронной отрасли будут возрастать. Чем более высокие требования предъявляются к современным образцам, комплексам, их точности, тем более ускоренными темпами должны развиваться метрология и измерительная техника. Из этого необходимо исходить, рассматривая будущее метрологии как в научном, так и в практическом плане.

С В.В. Быкановым беседовала Г. Ф. Куликова 


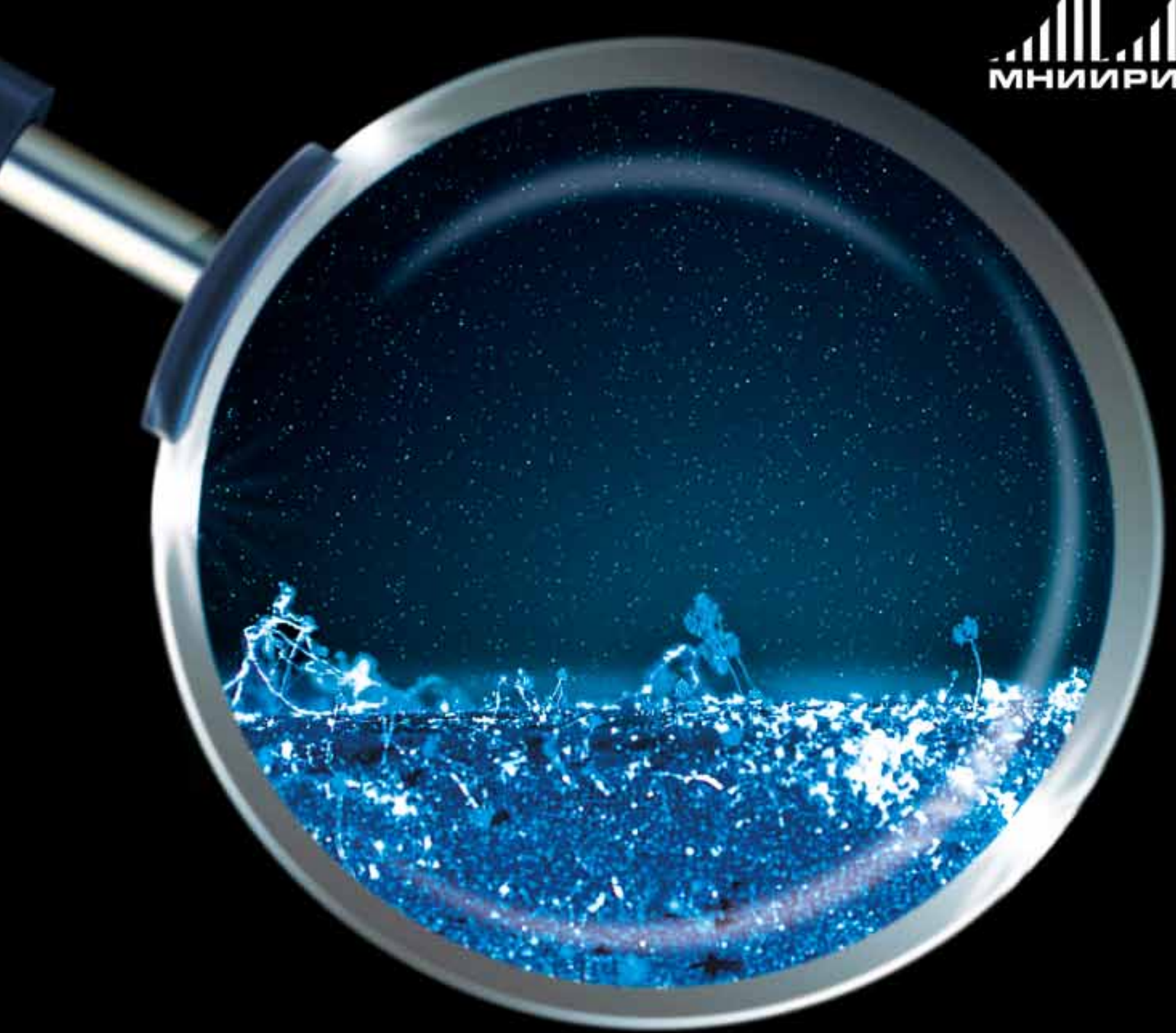

\section{ИСПЫТАНИЯ НА ВОЗДЕЙСТВИЕ ПЛЕСНЕВЫХХ ГРИБОВ}

Испытательный центр имеет санитарно-эпидемиологическое заключение и лицензию на право деятельности с микроорганизмами III и IV групп патогенности их штаммов. Испытания ЭКБ отечественного производства проходят под контролем 198 ВП МО РФ.

ФГУП мMнИИРИП-

Головная научно-исследовательская организация Минпромторга России в области ЭКБ www.mnilipipu

Московская область, г. Мытищи, ул. Колпакова, д. 2а 